\title{
From the Editor of Sexuality and Disability: A Time to Pause, Reflect, Appreciate, Learn, Share Feelings and Support
}

\section{Sigmund Hough ${ }^{1}$}

Published online: 24 October 2020

(c) Springer Science+Business Media, LLC, part of Springer Nature 2020

The journal, Sexuality and Disability, continues to be a professional home and a place of professional rejuvenation for study. Many have followed the journal over the decades since the 1970's. If you are new to the journal, we always give to you a "BIG WELCOME" and invite you to participate as a reader, author, academician, clinician, educator, service provider, researcher, advocate, or person seeking information. Over the years of contribution to the literature on sexuality and disability healthcare, we have been a part of the growth, understanding, and advocacy. Most important, we continue to be a part of the change in how we look and examine the topic, the needs, and the response in terms of best practice-evidence based approaches. With the intelligence, experience, motivation, and supportive dedication from our authors, readership, international peer reviewers and editorial board members, and resources combined with valuable guidance from the Springer Staff; our journal's mission continues to be meaningful. This international effort continues as a strength in the field of sexuality and disability.

Since 1978, Sexuality and Disability has pushed for pragmatic knowledge to have impact on education, research, and practice. Sexuality and Disability makes available original impact articles addressing the mental health and medical healthcare aspects of sexuality in relation to rehabilitation, hospital, academic, and community settings, publishing upto-date articles, case studies, clinical practice reports, reviews, featured articles, historical articles, special grand rounds topics, brief research reports, and survey data reports. Value benefit is provided to authors through worldwide electronic exposure and professional access, while readership gains knowledge from scholarly contributions which advance the field through research, evidence-based, best-practice and educational articles. Individual contributions from the local and international community delivers a wealth of information with broad perspectives on the topic of sexuality and disability.

The year 2020 calls for us to Pause, Reflect, Appreciate, Learn, Share Feelings and Support.

We wish health, safety and healing for our global readership community.

Thank you for joining our professional efforts.

Sigmund Hough

Sigmund_Hough@hms.harvard.edu

Boston, MA, USA 
Publisher's Note Springer Nature remains neutral with regard to jurisdictional claims in published maps and institutional affiliations. 